\title{
H3K9 tri-methylation at Nanog times differentiation commitment and enables the acquisition of primitive endoderm fate.
}

\author{
A. Dubois ${ }^{1}$, L. Vincenti ${ }^{1}$, A. Chervova ${ }^{1}$, S. Vandormael-Pournin ${ }^{1}$, M. Cohen-Tannoudji ${ }^{1}$, and P. Navarro ${ }^{1, *}$ \\ ${ }^{1}$ Epigenomics, Proliferation, and the Identity of Cells, Department of Developmental and Stem Cell Biology, Institut Pasteur, CNRS UMR3738, 75015 Paris, France \\ *Corresponding author: pnavarro@pasteur.fr
}

\begin{abstract}
Mouse Embryonic Stem (ES) cells have an inherent propensity to explore distinct gene-regulatory states associated with either self-renewal or differentiation. This property is largely dependent on ERK activity, which promotes silencing of pluripotency genes, most notably of the transcription factor Nanog. Here, we aimed at identifying repressive histone modifications that would mark the Nanog locus for inactivation in response to ERK activity. We found histone $\mathrm{H3}$ lysine 9 tri-methylation (H3K9me3) focally enriched between the $N a n o g$ promoter and its $-5 \mathrm{~kb}$ enhancer. While in undifferentiated ES cells H3K9me3 at Nanog depends on ERK activity, in somatic cells it becomes ERKindependent. Moreover, upon deletion of the region harbouring H3K9me3, ES cells display reduced heterogeneity of NANOG expression, delayed commitment into differentiation and impaired ability to acquire a primitive endoderm fate. We suggest that establishment of irreversible $\mathrm{H3K} 9 \mathrm{me} 3$ at specific master regulators allows the acquisition of particular cell fates during differentiation.
\end{abstract}

\section{Introduction}

Mouse Embryonic Stem (ES) cells are derived from preimplantation embryos and recapitulate numerous properties of the pluripotent inner cell mass of the blastocyst ${ }^{1}$. In vivo, the culmination of pluripotency - the ability to give rise to all three somatic germ layers - takes place when the primitive endoderm - a source of extra-embryonic tissues - segregates from the epiblast, the founder of the embryo proper ${ }^{2}$. This segregation is strictly controlled by the transcription factor Nanog, which is required to form the epiblast ${ }^{\mathbf{3}, \mathbf{4}}$ and, additionally, stimulates FGF4 production. This extracellular signal is then transduced into neighbouring cells by ERK activity, silencing Nanog and opening a window of opportunity to undergo commitment into primitive endoderm differentiation $^{\mathbf{5 - 1 0}}$. This binary cell fate decision is characterised by substantial heterogeneity of NANOG expression, which creates the conditions required for epiblast and primitive endoderm specification ${ }^{\mathbf{1 0}}$. Subsequently, Nanog expression is downregulated in the epiblast, eliciting the establishment of somatic differentiation ${ }^{\mathbf{1 1}}$. In vitro, ES cells also exhibit extensive Nanog heterogeneity: while NANOGpositive cells self-renew efficiently, NANOG-negative cells are prone for differentiation even though they remain uncommitted and can spontaneously revert to the Nanog-expressing state $\mathbf{1 2 - 1 6}$. Notably, NANOG-negative cells spontaneously generated in culture or by homozygous targeted deletion, show increased differentiation propensity towards both primitive endoderm and somatic fates ${ }^{\mathbf{1 1 - 1 6}}$. NANOG heterogeneity has been proposed to result from several mechanisms. On the one hand, it has been suggested to result from the architecture and the topology of the pluripotency network ${ }^{17-19}$; on the other, it is known to strongly depend on extrinsic cues, such as LIF/STAT3, WNT/GSK3b and FGF/ERK signalling $\mathbf{1 4 , 1 5 , 2 0 , 2 1}$. For both, specific regulatory properties and their inherent stochastic nature have been suggested to play a role ${ }^{22}$. Nevertheless, ERK activity has emerged as a key trigger of Nanog heterogeneity, in line with its general role in eliciting exit from pluripotency ${ }^{23,24}$. However, little is known about the chromatin-based aspects of Nanog heterogeneity. More specifically, it is unknown whether specific chromatin modifications ${ }^{\mathbf{2 5}}$ contribute to the stabilisation of the NANOG-negative state, which has been shown to be perpetuated for several cell divisions during self-renewal. Indeed, temporal analysis of NANOG fluctuations across cell generations has shown that the progeny of NANOG-negative cells is enriched in cells that maintain Nanog silencing, even though they can revert back and re-express NANOG ${ }^{26}$. This stability of the NANOG-negative state sets Nanog heterogeneity apart from other phenomena of gene expression heterogeneity, generally characterised by fast switching dynamics resulting from intrinsic and extrinsic noise or encoded in regulatory networks themselves ${ }^{27,28}$.

In this study, we aimed at identifying histone modifications associated with gene repression that would be: (i) differentially enriched at the Nanog locus when it is active or inactive; (ii) controlled by the signalling pathways associated with heterogeneity; (iii) heritable from mother to daughter cells ${ }^{29}$. We found histone $\mathrm{H} 3$ lysine 9 tri-methylation ${ }^{\mathbf{3 0}}$ (H3K9me3), enriched between the Nanog promoter and its $-5 \mathrm{~kb}$ enhancer ${ }^{31,32}$, to fulfil these criteria. Deletion of the region harbouring $\mathrm{H} 3 \mathrm{~K} 9 \mathrm{me} 3$ at Nanog was associated with reduced NANOG heterogeneity, delayed commitment into differentiation and, most notably, defective differentiation along the primitive endoderm lineage. Moreover, our data also suggests that during differentiation, $\mathrm{H} 3 \mathrm{~K} 9 \mathrm{me} 3$ at Nanog becomes independent from ERK activity. Hence, we propose that the timely establishment of ERK-independent H3K9me3 at Nanog marks commitment into differentiation and impacts cell fate acquisition in a lineage-dependent manner. 

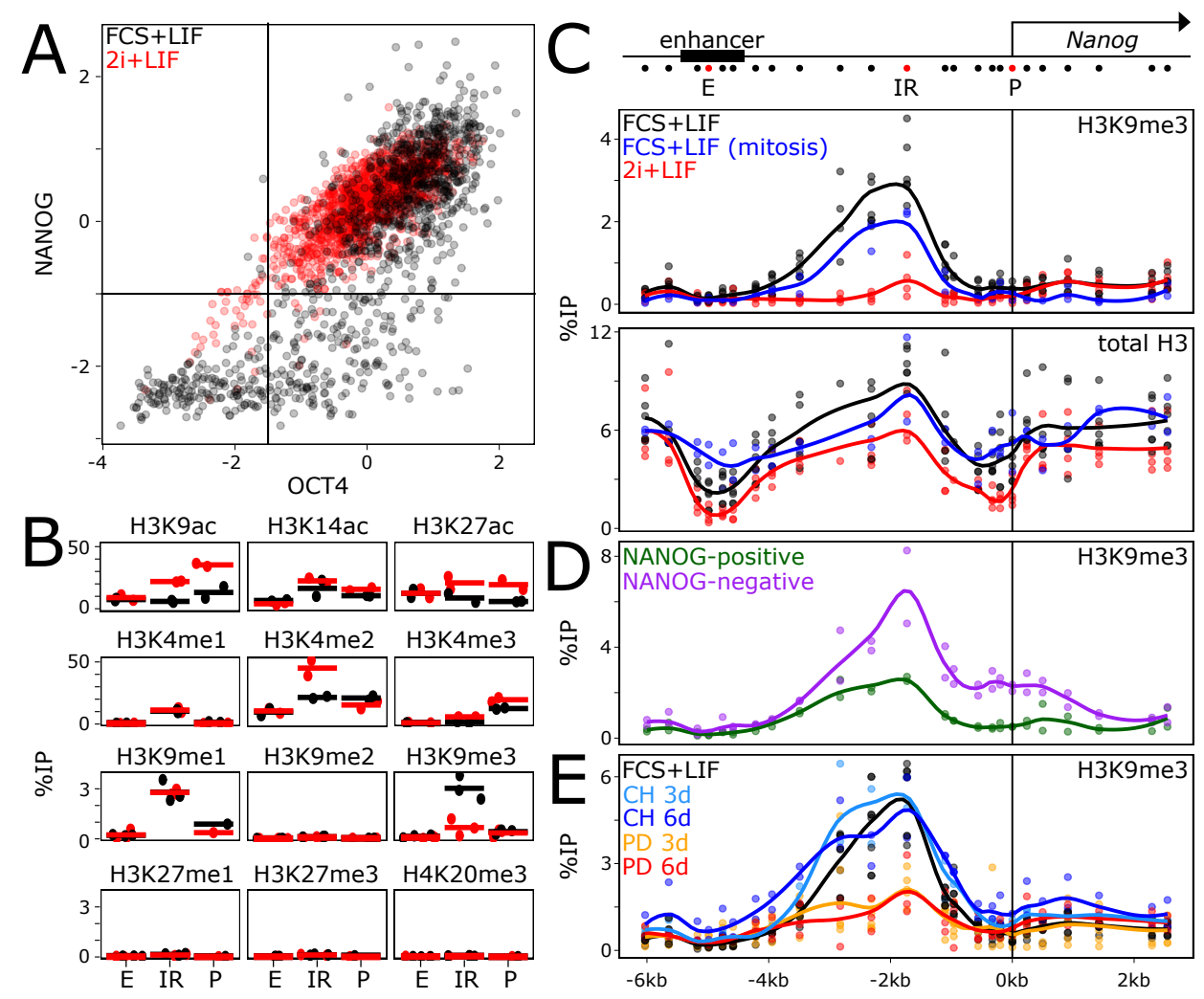

Fig. 1. Mitotically stable, ERK-dependent H3K9me3 at the Nanog locus. (A) Quantification of OCT4 (z score; X-axis) and NANOG ( $z$ score; $Y$-axis) levels as assessed by immunostaining in ES cells cultured in FCS+LIF (black, $n=1125$ ) and $2 i+$ LIF (read, $n=1445$ ). (B) ChIPqPCR of several histone modifications as indicated, at three positions of the Nanog locus (the Nanog promoter, P; the Nanog -5kb enhancer, $\mathrm{E}$; an intervening region, IR, located $1.7 \mathrm{~kb}$ of the Nanog transcription start site; see map on (C)) in ES cells cultured in FCS+LIF (black) or in $2 \mathrm{i}+$ LIF (red). Each dot represents the percentage of immunoprecipitation (\%IP; Y-axis) of independent replicates and the bar the corresponding mean. (C-E) Extended profile of $\mathrm{H} 3 \mathrm{~K} 9 \mathrm{me} 3$ or total $\mathrm{H} 3$, as indicated, across the Nanog locus (X-axis represents genomic distances in $\mathrm{kb}$ with respect to the Nanog transcription start site, as schematised on top), in ES cells cultured as indicated in each plot. Each dot represents the percentage of immunoprecipitation (\%IP; Y-axis) of independent replicates and the line the corresponding loess regression.

\section{Results}

\section{ERK-dependent, mitotically stable, H3K9me3 at the} Nanog locus in ES cells.

To explore the involvement of chromatin marks potentially distinguishing active and inactive Nanog states, we first performed a comparison of ES cell populations exhibiting heterogeneity, cultured in FCS+LIF (Fig.1A), with highly homogeneous populations obtained by double inhibition of ERK and GSK3b (2i+LIF; Fig.1A). While several euchromatic marks associated with active transcriptional states were found more enriched in $2 \mathrm{i}+\mathrm{LIF}$, as expected, we observed a single repressive mark, $\mathrm{H} 3 \mathrm{~K} 9 \mathrm{me} 3$, to be enriched in FCS+LIF and lost in 2i+LIF (Fig.1B). H3K9me3 was present neither at the promoter (P in Fig.1B) nor at the enhancer (E in Fig.1B); rather, we detected H3K9me3 in the intervening region (IR in Fig.1B). To further characterise H3K9me3, we performed a high-resolution analysis of the Nanog locus (Fig.1C, top), which confirmed the presence of a robust peak of $\mathrm{H} 3 \mathrm{~K} 9$ me3 between the enhancer and the promoter in FCS+LIF exclusively (Fig.1C). Analysis of total H3 confirmed the specificity of H3K9me3 enrichment (Fig.1C), which cannot be merely attributed to changes in nucleosome positioning or occupancy. Moreover, we observed good retention of H3K9me3 at Nanog in mitotic ES cells (Fig.1C), where drastic changes in nucleosomal densities could also be observed at the Nanog enhancer ${ }^{33}$ (Fig.1C). Next, we used a previously described Nanog-GFP reporter ${ }^{11}$ to sort Nanog-positive and -negative ES cells by FACS. We observed that H3K9me3 was more prominent in Nanog-negative cells, with clear spreading towards the promoter (Fig.1D). Finally, we assessed the temporal ERK and GSK3b dependencies of H3K9me3 at Nanog. In 3 days of ERK inhibition with PD0325901, which induce high and homogeneous NANOG expression (Fig.S1), H3K9me3 was significantly reduced (PD in Fig.1E), whereas even after 6 days of GSK3b inhibition with CHIR99021, H3K9me3 levels remained globally unchanged (CH in Fig.1E). Hence, the repressive H3K9me3 mark shows ideal properties to play a role in Nanog heterogeneity as it is readily dependent on ERK activity, fully lost in homogeneous NANOG populations, over-enriched in Nanognegative cells, and maintained during mitosis.

\section{H3K9me3 at Nanog impacts NANOG heterogeneity.}

To study the relevance of $\mathrm{H} 3 \mathrm{~K} 9 \mathrm{me} 3$ at Nanog, we used a Crispr/Cas9 approach deleting $1.8 \mathrm{~kb}$ between the enhancer and promoter (Fig.2A, red box). Two clones $(\Delta \mathrm{K} 9.1$ and $\Delta K 9.2)$ were confirmed as homozygously deleted with a complete absence of H3K9me3 (Fig.2A). Nanog mRNA levels were slightly upregulated in $\Delta \mathrm{K} 9$ cells (Fig.2B), which presented a clear shift in NANOG expression to higher and more homogeneous levels, with a strong reduction of the proportion of cells expressing no or low NANOG (Fig.2C). In agreement with the low upregulation of Nanog in $\Delta \mathrm{K} 9$ cells, we observed a nearly insignificant increase in selfrenewal efficiency, as determined by clonal assays. However, $\Delta \mathrm{K} 9$ cells were more recalcitrant to efficiently differentiate upon LIF withdrawal (Fig.2D). Next, we performed RNA-seq analysis to compare wild-type and $\Delta K 9$ cells (Table S1), which confirmed a small increase in Nanog expression (FDR $<0.05$; Fig.S2A). We identified 235 and 402 genes that were up- or down-regulated, respectively, in both $\Delta \mathrm{K} 9$ clones $(\mathrm{FDR}<0.05$ and $\operatorname{abs}(\log 2 \mathrm{FC})>0.3$; Fig.S2B $)$. Even though differentially expressed genes exhibited small 


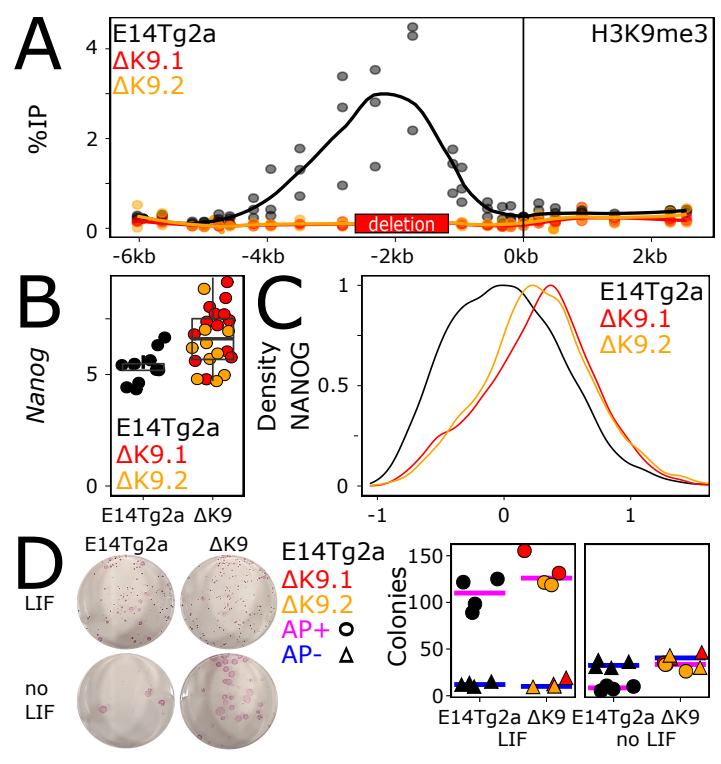

Fig. 2. The Nanog region harbouring H3K9me3 enables heterogenous NANOG expression. (A) H3K9me3 profile across the Nanog locus, presented as in Figure $1 \mathrm{C}$, in wild-type ES cells (E14Tg2a, black) and in two mutant derivatives $(\Delta \mathrm{K} 9.1$ and $\Delta \mathrm{K} 9.2$, in red and orange respectively), carrying a deletion of the region enriched for H3K9me3 (red box on the X-axis). (B) Expression of Nanog mRNA levels (normalised to $T b p$ ) assessed by RT-qPCR in wild-type (E14Tg2a, black) and mutant clones (red and orange). Each dot represents the level of Nanog mRNA of independent replicates and the boxplots the corresponding median (bar), 25-75\% percentiles (box) and 1.5-folds the inter-quartile range (whiskers). (C) Histogram representing the density (Y-axis) of NANOG expression levels (X-axis; log2(mean intensity) corrected to the E14Tg2a median of each experiment, $n=2)$ in wild-type (E14Tg2a, black; $n=8191)$ or mutant cells $(\Delta K 9.1$ and $\Delta K 9.2$ in red and orange, respectively; $n=3835,3812$ ) as assessed by immuno-staining. (D) Representative alkaline-phosphatase staining of ES cell colonies for the indicated cell lines and culture conditions. The plot shows the number of alkaline-phosphatase (AP) positive (circles) and negative colonies (triangles) in wild-type (E14Tg2a, black) and $\Delta \mathrm{K} 9$ cells (red and orange). Each dot represents an independent replicate and the bar the corresponding median for AP+ (pink) or AP- (blue) colonies.

fold changes (Fig.S2C), consistent with the small increase in Nanog expression observed in $\Delta \mathrm{K} 9$ cells, they were nonetheless found enriched in the vicinity of NANOG binding regions, compared with regions bound by OCT4/SOX 2 but not $\mathrm{NANOG}^{\mathbf{3 3 , 3 4}}$ (Fig.S2D). We conclude that the deletion of the region harbouring $\mathrm{H} 3 \mathrm{~K} 9 \mathrm{me} 3$ at the Nanog locus reduces the capacity of ES cells to explore the NANOG-negative state efficiently, leading to a measurable resistance to differentiate.

\section{ERK-independent H3K9me3 at Nanog in somatic cells.}

We next aimed at characterising the status of $\mathrm{H} 3 \mathrm{~K} 9 \mathrm{me} 3$ at Nanog in non-pluripotent cells. First, we established the H3K9me3 profiles over the Nanog locus in several cell types where Nanog has been silenced during development (Fig.3A). H3K9me3 was systematically found enriched between the Nanog enhancer and promoter, albeit at different levels. In Trophectoderm Stem (TS) cells, the levels found at Nanog were lower than in FCS+LIF ES cells, except at the Nanog promoter where some spreading was detected. In Extra-embryonic Endoderm (XEN) cells, the levels of $\mathrm{H} 3 \mathrm{~K} 9 \mathrm{me} 3$ were found higher, exhibiting spreading towards the promoter. Finally, in Mouse Embryonic Fibroblasts (MEFs), the level of $\mathrm{H} 3 \mathrm{~K} 9 \mathrm{me} 3$ was particularly high, with prominent invasion of the Nanog promoter and gene body. Therefore, we conclude that while $\mathrm{H} 3 \mathrm{~K} 9 \mathrm{me} 3$ is found

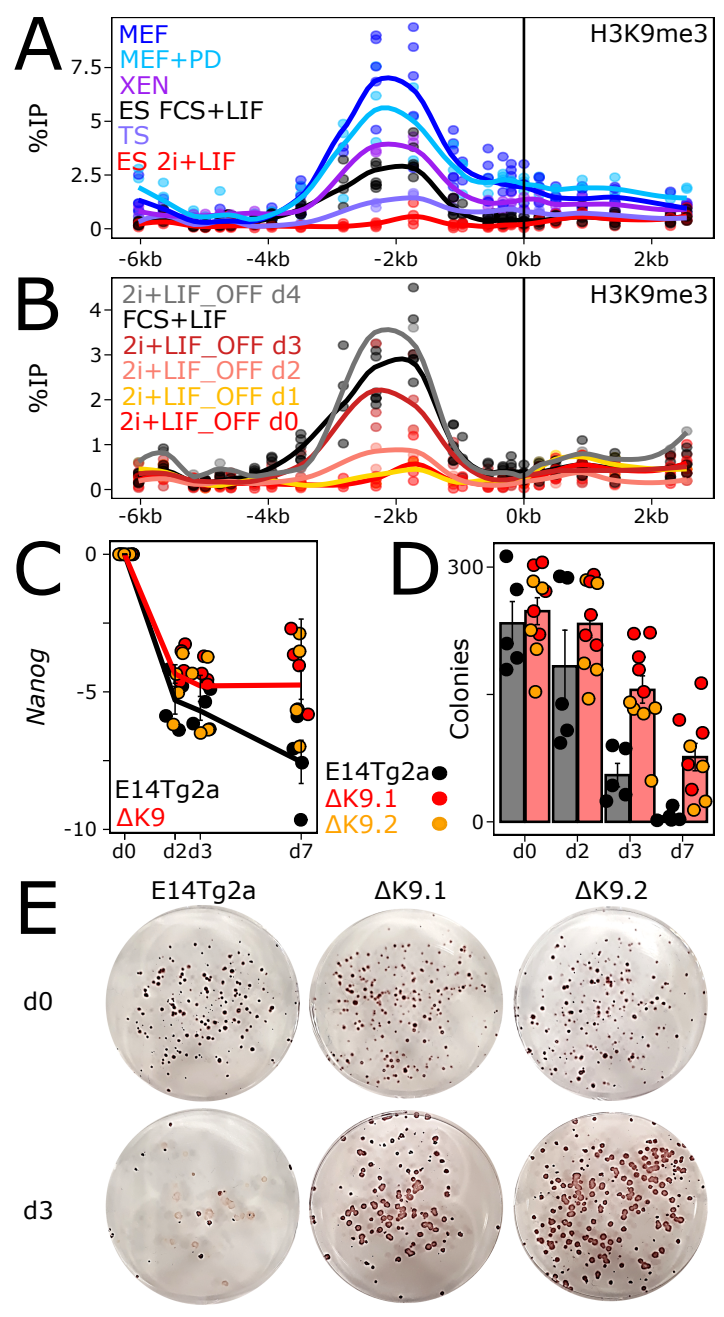

Fig. 3. H3K9me3 at Nanog times commitment into differentiation. (A) H3K9me3 profile across the Nanog locus, presented as in Figure $1 \mathrm{C}$, in the indicated cell lines and conditions. (B) Identical profiles for ES cells undergoing differentiation (labelled 2i+LIF_OFF) for the indicated number of days. (C) Nanog Log2 relative mRNA levels ( $\mathrm{d} 0$ set to 1 ) measured by RT-qPCR and normalised to Tbp, during ES cell differentiation in the indicated cell lines. Each dot represents an independent replicate and the line the corresponding mean with standard errors. (D) Number of alkaline-phosphatase positive colonies obtained after switching to $2 \mathrm{i}+\mathrm{LIF}$ wild-type (E14Tg2a, black) and $\Delta K 9$ (red and orange) cells seeded clonally and differentiated for the number of days indicated on the X-axis. Each dot represents an independent replicate and the histogram the corresponding mean and standard error. (E) Representative alkaline-phosphatase staining of ES cell colonies cultured in $2 \mathrm{i}+$ LIF after 0 (top) or 3 (bottom) days of differentiation for the indicated cell lines.

at Nanog in the three cell types analysed, its absolute levels and the degree of spreading towards the promoter are variable. This suggests that a certain level of developmental specificity impacts $\mathrm{H} 3 \mathrm{~K} 9$ methylation at Nanog. Moreover, and in contrast to ES cells, the inhibition of ERK in MEFs did not abolish H3K9me3 at Nanog, which remained robustly enriched (Fig.3A). This indicates that during differentiation, when Nanog silencing becomes irreversible, H3K9me3 at Nanog is liberated from its strict dependency on ERK.

\section{H3K9me3 at Nanog controls the timing of commitment into differentiation.}

We then aimed at assessing the dynamics of $\mathrm{H} 3 \mathrm{~K} 9 \mathrm{me} 3$ at Nanog during ES cell differentiation. We used a simple protocol starting from $2 \mathrm{i}+\mathrm{LIF}$ (absence of $\mathrm{H} 3 \mathrm{~K} 9 \mathrm{me} 3$ ) and 


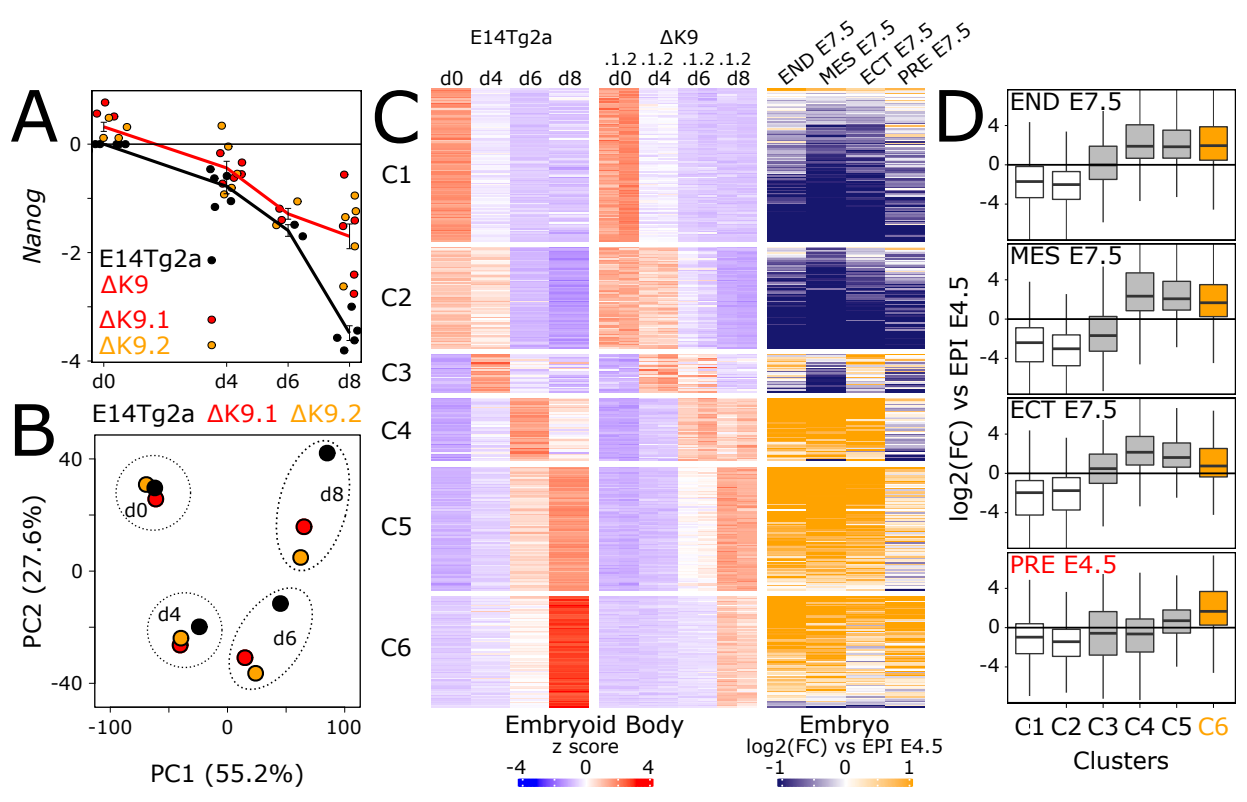

Fig. 4. The lack of H3K9me3 at Nanog leads to delayed differentiation. (A) Log2 Nanog mRNA levels measured by RT-qPCR and normalised to Tbp during embryoid body differentiation in the indicated cell lines. Each dot represents an independent replicate and the line the corresponding mean with standard errors. (B) Principal Component Analysis of 16336 transcripts quantified by RNA-seq (Transcripts Per Million above 1 in at least one sample) in wild-type (E14Tg2a, black; $n=3$ ) and $\Delta K 9$ (red and orange; $n=3$ for each) cells undergoing embryoid body differentiation for the indicated number of days. (C) Heatmap of 4100 transcripts displaying significant gene expression changes during embryoid body differentiation (DEseq FDR $<0.05$ and $a b s(\log 2 F C)>1$ in at least one comparison to undifferentiated cells; $n=3$ for each cell line), clustered by $k$-means ( $\mathrm{k}=6$; 50 iterations; 50 random starts) after $\mathrm{z}$ score normalisation. Left, relative gene expression ( $\mathrm{z}$ score) in wild-type (E14Tg2a) and $\Delta \mathrm{K} 9$ cells during embryoid body differentiation; right, corresponding log2 fold-changes of each developmental stage indicated on top versus E4.5 epiblast, as previously reported ${ }^{36}$. END: endoderm; MES: mesoderm; ECT: ectoderm; PRE: primitive endoderm; EPI: epiblast. (D) Boxplot (median; 25-75\% percentiles; 1.5 -folds the inter-quartile range) of log2FC shown in (C) for each cluster. Cluster $\mathrm{C} 6$ is highlighted in orange.

based on the withdrawal of LIF and of ERK and GSK3b inhibitors (Fig.S3A). We observed a step-wise increase of H3K9me3 (Fig.3B): if it remained low during the first 48h, it suddenly appeared after 3 days and only slightly increased after 4 days. Somehow unexpectedly, this appearance of H3K9me3 did not correlate with a particularly strong reduction of Nanog expression (Fig.3C). In fact, we observed Nanog downregulation taking largely place during the first 48h, in the absence of high levels of H3K9me3. However, while Nanog expression continued to decrease during differentiation of wild-type cells, we observed that $\Delta \mathrm{K} 9$ clones displayed a stabilisation of low Nanog expression after the sharp decrease occurring during the first 2 days (Fig.3C), despite an efficient differentiation (Fig.S3A). This different behaviour of Nanog expression in $\Delta \mathrm{K} 9$ clones, temporally correlated with the time at which $\mathrm{H} 3 \mathrm{~K} 9 \mathrm{me} 3$ is established in wild-type cells, prompted us to determine if commitment into differentiation - the moment at which cells cannot easily come back to an undifferentiated state - was altered in $\Delta \mathrm{K} 9$ cells. For this, we seeded wild-type and $\Delta \mathrm{K} 9$ cells at clonal density and after 2, 3 or 7 days of differentiation, we replaced the culture medium back to 2i+LIF: only cells that have not yet irreversibly lost their capacity to self-renew will survive, proliferate and form undifferentiated, alkaline-phosphatasepositive colonies $^{35}$ (Fig.3D,E). In wild-type cells, we observed a striking coincidence of the time of commitment, taking place between days 2 and 3, with the appearance of H3K9me3 at Nanog. In $\Delta \mathrm{K} 9$ clones, however, we observed a significant number of alkaline-phosphatase-positive colonies after 3 and even 7 days of differentiation, testifying of de- lay in commitment. Altogether, these analyses suggest that in 2i+LIF ES cells, H3K9me3 at Nanog is established during differentiation, when it marks the irreversible commitment into effective differentiation. Yet, it is not strictly required for differentiation per se and rather enables the appropriate timing of commitment.

\section{$\Delta K 9$ cells exhibit delayed differentiation.}

Given the delay in differentiation commitment observed in $\Delta \mathrm{K} 9$ clones, we monitored the expression of several genes reflecting the loss of pluripotency and the transition to a differentiated state ${ }^{35}$ (Fig.S3B). While naïve pluripotency genes (Esrrb, Klf4, Prdm14, Rexl) showed a less drastic downregulation, mimicking Nanog expression, differentiation markers (Fgf5, Dnmt3b, Otx2, Wnt3) showed delayed dynamics. Next, we differentiated wild-type and $\Delta \mathrm{K} 9$ cells into Embryoid Bodies (EBs), a paradigm that recapitulates the establishment of multiple lineages. At the morphological level we observed $\Delta \mathrm{K} 9 \mathrm{~EB}$ s to be often characterised by defective sealing at their periphery (Fig.S4A). Moreover, cellular outgrowths derived from $\Delta \mathrm{K} 9$ EBs also exhibited obvious differences compared to those derived from wild-type EBs, with less apparent multi-lineage differentiation (Fig.S4A). Gene expression analyses of EBs after d4, d6 and d8 of differentiation confirmed the attenuated downregulation of Nanog expression (Fig.4A). Moreover, PCA analysis of RNA-seq profiling (Table S1) highlighted a transcriptome-wide delay of both $\Delta \mathrm{K} 9$ clones, starting at $\mathrm{d} 4$ and progressively increasing through time (Fig.4B). Gene ontology analysis of the top 1000 loadings of the PCA identified focal adhesion genes among the most enriched cellular components 

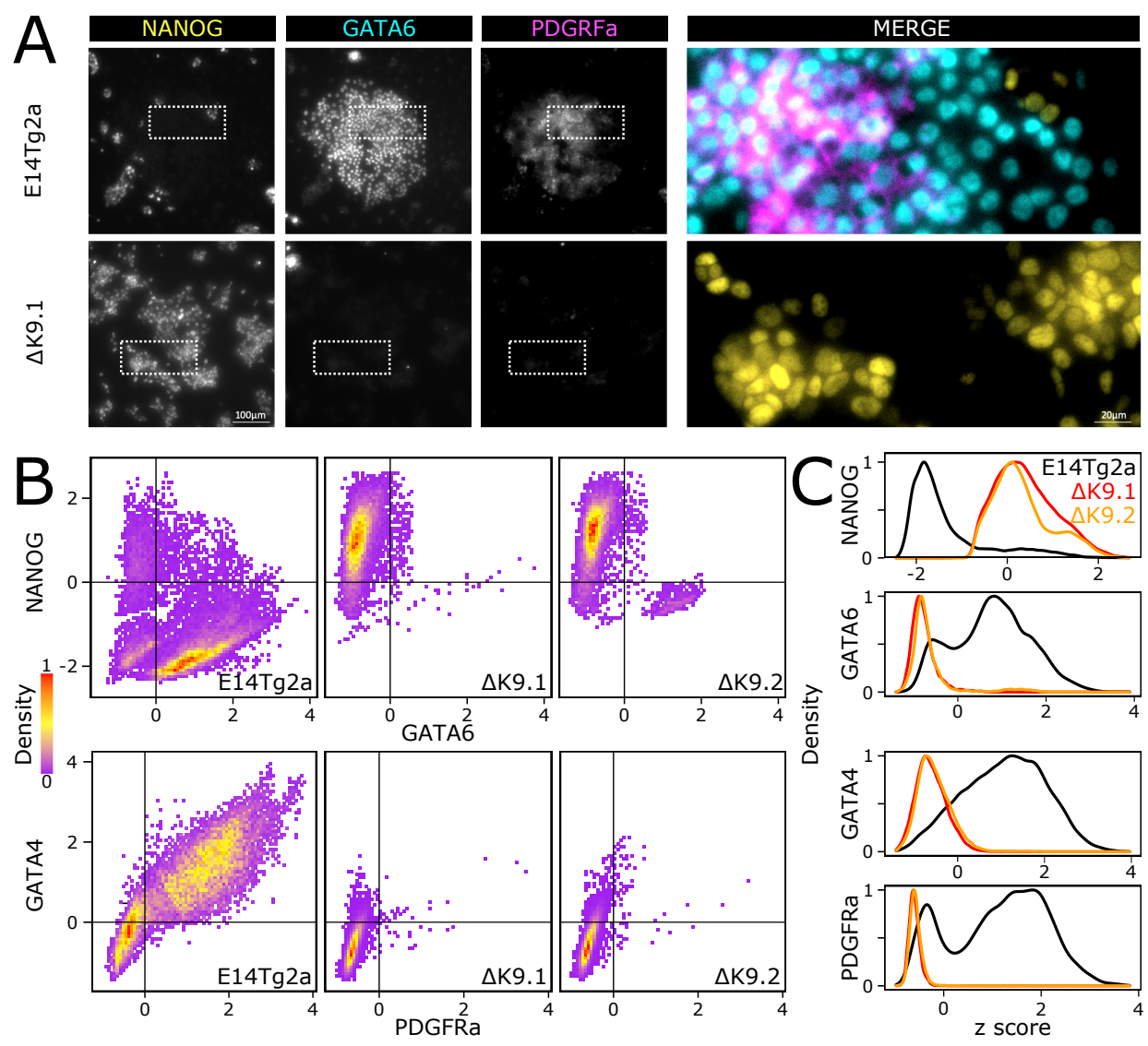

Fig. 5. The lack of $\mathrm{H} 3 \mathrm{~K} 9 \mathrm{me} 3$ at Nanog abolishes primitive endoderm differentiation. (A) Representative immuno-staining of ES cells (E14Tg2a, top; $\triangle \mathrm{K} 9.1$, bottom) subject to a directed differentiation protocol into primitive endoderm. (B-C) Quantification of dual immuno-staining for NANOG, GATA6 and GATA4, PDGRFa in E14Tg2a $(n=19507,20641), \Delta K 9.1(n=11348,19476)$ and $\Delta K 9.2(n=9713,19742)$ cells differentiated as in $(A)$.

(GO:0005925; $\mathrm{p}<10^{-5}$ ), in line with our morphological observations (Fig.S4A). Therefore, the lack of H3K9me3 at Nanog is strongly associated with delayed differentiation, as evaluated with three distinct differentiation paradigms (Fig.2D, Fig.S3B and Fig.4B).

\section{The absence of H3K9me3 at Nanog leads to major defects in primitive endoderm differentiation.}

To further explore the molecular nature of the defects observed during EB differentiation, we first identified around 4000 genes displaying temporal gene expression changes in either differentiating wild-type or mutant cells compared to their undifferentiated controls $(\mathrm{FDR}<0.05, \operatorname{abs}(\log 2 \mathrm{FC})>1$; Table S1). These genes were then clustered using k-means; this allowed us to identify 6 groups of genes displaying different expression dynamics during EB differentiation (Fig.4C, left; Table S1). While all identified clusters underscored the delay into differentiation, one in particular, cluster c6, showed a blatant attenuation of gene upregulation at $\mathrm{d} 8$. To characterise each cluster relative to known developmental trajectories, we plotted the fold-change reported in a previous study $^{\mathbf{3 6}}$ where embryonic endoderm, mesoderm and ectoderm cells of E7.5 embryos, as well as primitive endoderm cells of E4.5 embryos, were directly compared to the E4.5 epiblast (Fig.4C, right). While clusters $\mathrm{c} 1$ and $\mathrm{c} 2$ showed a marked downregulation upon epiblast differentiation into all lineages, cluster c3 to c6 displayed a clear upregulation in at least one E7.5 lineage. Notably, cluster c6, which shows the strongest $\Delta \mathrm{K} 9$ vs wild-type differences, was the only one enriched for genes displaying a prominent upregulation in the primitive endoderm with respect to the epiblast (Fig.4D). Analysis of primitive endoderm markers such as Gata6, Gata4 and Sox 17 during EB differentiation confirmed the altered induction of these genes (Fig.S4B).

Finally, in light of these results, we wanted to ascertain whether the defective primitive endoderm signature identified in EBs implies a deficiency in the capacity of $\Delta \mathrm{K} 9$ clones to engage in primitive endoderm differentiation. Thus, we challenged wild-type and $\Delta \mathrm{K} 9 \mathrm{ES}$ cells with a primitive endoderm differentiation protocol ${ }^{37}$ (Fig.S5). In wild-type cells, but not in $\Delta \mathrm{K} 9$ clones, we observed the appearance of endoderm-like cell clusters from day 4 onwards. Moreover, $\Delta \mathrm{K} 9$ clones showed increased cell death. Immunofluorescence of NANOG, GATA6, GATA4 and PDGFRa, confirmed NANOG silencing in cells expressing primitive endoderm markers, as expected (Fig.5A,B,C). In $\Delta \mathrm{K} 9$ clones, however, NANOG expression was prominent and the appearance of cells expressing primitive endoderm markers anecdotical. Therefore, $\Delta \mathrm{K} 9$ cells are not able to undergo directed differentiation into primitive endoderm. We conclude that H3K9me3 is required to stably silence Nanog during differentiation and that failing to do so has different consequences depending on the differentiation lineage, with primitive endoderm being particularly sensitive. 


\section{Discussion}

Gene expression heterogeneity has emerged as a main motor of lineage diversification during development, particularly in stem cell and progenitor populations: upon appropriate stimuli, these expression differences are translated into an effective decision-making process that culminates in commitment ${ }^{\mathbf{2 2 , 2 7 , 2 8}}$. When these heterogeneities are dynamic, such as in the case of Nanog and ES cells, the fluctuating expression is eventually fixed. A likely model accounting for the transition from reversible to irreversible silencing involves epigenetic repression, in the sense of heritable chromatin states incompatible with transcription that do not depend on the original triggers ${ }^{38}$. The acquisition of epigenetic repression, including $\mathrm{H} 3 \mathrm{~K} 9 \mathrm{me} 3^{\mathbf{3 9}}$, is indeed perceived as a general mean to restrict developmental fate choices as cells differentiate ${ }^{\mathbf{4 0}}$. Accordingly, we show that Nanog silencing during differentiation is accompanied by $\mathrm{H} 3 \mathrm{~K} 9 \mathrm{me} 3$, which irreversibly locks its expression and thus contributes to commitment into differentiation. Two observations, however, indicate that additional complexity may characterise both Nanog silencing and its developmental implications.

While epigenetic repression is often instated de novo during differentiation, for example at $O c t 4^{\mathbf{4 1}}$, the regulation of Nanog appears to involve an intermediary state where $\mathrm{H} 3 \mathrm{~K} 9 \mathrm{me} 3$ is already established but not yet fixed. In undifferentiated cells, H3K9me3 is readily detected at Nanog, particularly in Nanog-negative cells. Moreover, it is transferred from mother to daughter cells during mitosis. However, it is strictly dependent upon ERK signalling, the main driver of NANOG heterogeneity. This mitotically-stable and ERK-dependent state of H3K9me3 confers to Nanog silencing the required stability to be inherited and, at the same time, sufficient flexibility to revert back to transcriptional activity. During differentiation (at least as judged by the analysis of embryonic fibroblasts), H3K9me3 becomes independent of ERK and, with respect to ERK, irreversible. Therefore, even if subjected to variations in ERK stimuli, Nanog will remain silent. In spite of these considerations, we suggest that $\mathrm{H} 3 \mathrm{~K} 9 \mathrm{me} 3$ at Nanog becomes epigenetic exclusively during differentiation, when it is not any longer dependent on its original trigger. Whether this transition is mediated by direct mechanisms operating at the locus, on the $\mathrm{H} 3 \mathrm{~K} 9 \mathrm{me} 3$-associated machinery, or linked to the general lack of strong epigenetic repression in ES cells ${ }^{\mathbf{4 2 , 4 3}}$, remains unknown. Nevertheless, these findings are reminiscent of the dependency of other repressive marks, such as H3K27me3, on LIF signalling and NANOG activity ${ }^{\mathbf{3 4}}$, suggesting a general vassalage of repressive chromatin marks to more dynamic regulators in undifferentiated ES cells. By displaying regulated dependencies towards signalling and/or transcription factor activity, repressive chromatin modifications may facilitate conditional heritability and excitability or, on the contrary, fixed gene expression states ${ }^{42}$.

Nanog is known to counteract differentiation when ectopically expressed at high levels ${ }^{11}$. Since the deletion of the region harbouring $\mathrm{H} 3 \mathrm{~K} 9 \mathrm{me} 3$ leads to a minor increase of
NANOG expression, it was not expected to block differentiation. After all, upon the collapse of the pluripotency network triggered by differentiation signals, Nanog would lose most of its activators and be downregulated, as we observed. Yet, the lack of H3K9me3 leads to a lack of complete Nanog silencing, providing an opportunity to evaluate the importance of fully repressing Nanog during differentiation. Similarly, as cells lacking $\mathrm{H} 3 \mathrm{~K} 9 \mathrm{me} 3$ at Nanog reduce their heterogeneity in a context where Nanog can nevertheless be downregulated (in contrast to ectopic expression systems), the importance of NANOG heterogeneity in lineage priming can also be inferred from our experimental setup. We observed delayed commitment and altered differentiation into all germ layers. Yet, the highest consequences affect genes normally upregulated in the primitive endoderm; remarkably, the lack of H3K9me3 at Nanog is incompatible with differentiation along this lineage. This observation underscores the relative importance of Nanog in repressing differentiation of somatic versus primitive endoderm lineages in ES cells. Furthermore, Nanog heterogeneity in ES cells has been proposed to either reflect the heterogeneity observed in early blastocysts, which cells of the inner mass can either express NANOG or GATA6, or the early downregulation of Nanog taking place around implantation to elicit somatic differentiation events of the epiblast $^{\mathbf{1 1 - 1 6}}$. Indirectly, thus, our results could be interpreted as Nanog heterogeneity and its subsequent full silencing being functionally associated to the epiblast versus primitive endoderm specification. In this regard, two observations are noteworthy. First, the repressive H3K27me3 mark has been shown to play a preponderant role in downregulating genes that prime ES cells for primitive endoderm differentiation ${ }^{\mathbf{4 4}}$. Second, Nanog sustains H3K27me3 in undifferentiated and early differentiating ES cells ${ }^{\mathbf{3 4}}$. In light of these findings and of our observation that the loss of $\mathrm{H} 3 \mathrm{~K} 9 \mathrm{me} 3$ also alters the differentiation balance between somatic and primitive endoderm lineages, we suggest that a signalling and transcription factor dialogue established through repressive histone methylation contributes to the epiblast versus primitive endoderm specification. In this model, ERK dynamically controls H3K9me3 at Nanog, which sustains H3K27me3 levels and keeps primitive endoderm genes in check, generating reversible and mosaic expression patterns associated with either epiblast or primitive endoderm fates.

Overall, our observations add to the notion that heterochromatin contributes to cell fate restriction during differentiation processes. They also suggest that these events are more nuanced in their action than it was anticipated, given the regulation of its dependency towards signalling cues in respect of its epigenetic potential and the differential impact that the ensuing stability of the repression may have in different lineages. Whether our findings can be extrapolated to other master regulators of pluripotency or to other developmental transitions represent important new avenues for the future.

Supplementary information Five supplementary figures accompany this manuscript, they can be found at the end of this document. Two Supplementary Tables and Methods are available online. 
Acknowledgements. This study was conceived by P.N with inputs from A.D. Experiments were designed and executed by A.D., with help from L.V., S.V-P. and M.C-T. Computational analyses were done by A.C. and P.N. The paper was written by P.N. with inputs from A.D. and M.C.T. The authors acknowledge the cytometry platform of Institut Pasteur for technical assistance and L. Bally-Cuif and S. Tajbakhsh for critical reading of the manuscript. P.N. and M.C-T. acknowledge the Labex Revive (Investissement d'Avenir; ANR-10-LABX-73), the Institut Pasteur and the CNRS for funding.

Declaration of interests. The authors declare no competing interests.

\section{References}

1: Martello G, Smith A. The nature of embryonic stem cells. Annu Rev Cell Dev Biol. 2014;30:647-75. doi: 10.1146/annurev-cellbio-100913-013116.

2: Chazaud C, Yamanaka Y. Lineage specification in the mouse preimplantation embryo. Development. 2016 Apr 1;143(7):1063-74. doi: 10.1242/dev.128314.

3: Mitsui K, Tokuzawa Y, Itoh H, Segawa K, Murakami M, Takahashi K, Maruyama M, Maeda M, Yamanaka S. The homeoprotein Nanog is required for maintenance of pluripotency in mouse epiblast and ES cells. Cell. 2003 May 30;113(5):631-42. doi: 10.1016/s0092-8674(03)00393-3.

4: Silva J, Nichols J, Theunissen TW, Guo G, van Oosten AL, Barrandon O, Wray J, Yamanaka S, Chambers I, Smith A. Nanog is the gateway to the pluripotent ground state. Cell. 2009 Aug 21;138(4):722-37. doi: 10.1016/j.cell.2009.07.039.

5: Nichols J, Silva J, Roode M, Smith A. Suppression of Erk signalling promotes ground state pluripotency in the mouse embryo. Development. 2009 Oct;136(19):3215-22. doi: 10.1242/dev.038893. Epub 2009 Aug 26.

6: Yamanaka Y, Lanner F, Rossant J. FGF signaldependent segregation of primitive endoderm and epiblast in the mouse blastocyst. Development. 2010 Mar;137(5):71524. doi: 10.1242/dev.043471. PMID: 20147376.

7: Frankenberg S, Gerbe F, Bessonnard S, Belville C, Pouchin P, Bardot O, Chazaud C. Primitive endoderm differentiates via a three-step mechanism involving Nanog and RTK signaling. Dev Cell. 2011 Dec 13;21(6):1005-13. doi: 10.1016/j.devcel.2011.10.019. PMID: 22172669.

8: Saiz N, Williams KM, Seshan VE, Hadjantonakis AK. Asynchronous fate decisions by single cells collectively ensure consistent lineage composition in the mouse blastocyst. Nat Commun. 2016 Nov 18;7:13463. doi: 10.1038/ncomms13463. PMID: 27857135.

9: Bessonnard S, Coqueran S, Vandormael-Pournin S, Dufour A, Artus J, Cohen-Tannoudji M. ICM conversion to epiblast by FGF/ERK inhibition is limited in time and requires transcription and protein degradation. Sci Rep. 2017 Sep 25;7(1):12285. doi: 10.1038/s41598-017-121200. PMID: 28947813.

10: Chazaud C, Yamanaka Y, Pawson T, Rossant J. Early lineage segregation between epiblast and primitive endoderm in mouse blastocysts through the Grb2-MAPK pathway. Dev Cell. 2006 May;10(5):615-24. doi: 10.1016/j.devcel.2006.02.020. PMID: 16678776.

11: Chambers I, Colby D, Robertson M, Nichols J, Lee S, Tweedie S, Smith A. Functional expression cloning of Nanog, a pluripotency sustaining factor in embryonic stem cells. Cell. 2003 May 30;113(5):643-55. doi: 10.1016/s0092-8674(03)00392-1. PMID: 12787505.

12: Chambers I, Silva J, Colby D, Nichols J, Nijmeijer B, Robertson M, Vrana J, Jones K, Grotewold L, Smith A. Nanog safeguards pluripotency and mediates germline development. Nature. 2007 Dec 20;450(7173):1230-4. doi: 10.1038/nature06403. PMID: 18097409.

13: Singh AM, Hamazaki T, Hankowski KE, Terada N. A heterogeneous expression pattern for Nanog in embryonic stem cells. Stem Cells. 2007 Oct;25(10):2534-42. doi: 10.1634/stemcells.2007-0126. Epub 2007 Jul 5. PMID: 17615266.

14: Kalmar T, Lim C, Hayward P, Muñoz-Descalzo S, Nichols J, Garcia-Ojalvo J, Martinez Arias A. Regulated fluctuations in nanog expression mediate cell fate decisions in embryonic stem cells. PLoS Biol. 2009 Jul;7(7):e1000149. doi: 10.1371/journal.pbio.1000149. Epub 2009 Jul 7. PMID: 19582141 ; PMCID: PMC2700273.

15: Abranches E, Guedes AM, Moravec M, Maamar H, Svoboda P, Raj A, Henrique D. Stochastic NANOG fluctuations allow mouse embryonic stem cells to explore pluripotency. Development. 2014 Jul;141(14):2770-9. doi: 10.1242/dev.108910. PMID: 25005472; PMCID: PMC6517831.

16: Canham MA, Sharov AA, Ko MS, Brickman JM. Functional heterogeneity of embryonic stem cells revealed through translational amplification of an early endodermal transcript. PLoS Biol. 2010 May 25;8(5):e1000379. doi: 10.1371/journal.pbio.1000379. PMID: 20520791; PMCID: PMC2876051.

17: Navarro P, Festuccia N, Colby D, Gagliardi A, Mullin NP, Zhang W, Karwacki-Neisius V, Osorno R, Kelly D, Robertson M, Chambers I. OCT4/SOX2-independent Nanog autorepression modulates heterogeneous Nanog gene expression in mouse ES cells. EMBO J. 2012 Dec 12;31(24):454762. doi: 10.1038/emboj.2012.321. Epub 2012 Nov 23.

18: Karwacki-Neisius V, Göke J, Osorno R, Halbritter F, Ng JH, Weiße AY, Wong FC, Gagliardi A, Mullin NP, Festuccia N, Colby D, Tomlinson SR, Ng HH, Chambers I. Reduced Oct4 expression directs a robust pluripotent state with distinct signaling activity and increased enhancer occupancy by Oct 4 and Nanog. Cell Stem Cell. 2013 May 2;12(5):531-45. doi: 10.1016/j.stem.2013.04.023.

19: Filipczyk A, Marr C, Hastreiter S, Feigelman J, Schwarzfischer M, Hoppe PS, Loeffler D, Kokkaliaris KD, Endele M, Schauberger B, Hilsenbeck O, Skylaki S, Hasenauer J, Anastassiadis K, Theis FJ, Schroeder T. Network plasticity of pluripotency transcription factors in embryonic stem cells. Nat Cell Biol. 2015 Oct;17(10):1235-46. doi: 10.1038/ncb3237. Epub 2015 Sep 21.

20: Wray J, Kalkan T, Gomez-Lopez S, Eckardt D, Cook A, Kemler R, Smith A. Inhibition of glycogen synthase kinase-3 alleviates Tcf3 repression of the pluripotency network and increases embryonic stem cell resistance to differentiation. Nat Cell Biol. 2011 Jun 19;13(7):838-45. doi: $10.1038 /$ ncb2267. 
21: Marks H, Kalkan T, Menafra R, Denissov S, Jones K, Hofemeister H, Nichols J, Kranz A, Stewart AF, Smith A, Stunnenberg HG. The transcriptional and epigenomic foundations of ground state pluripotency. Cell. $2012 \mathrm{Apr}$ 27;149(3):590-604. doi: 10.1016/j.cell.2012.03.026.

22: Martinez Arias A, Brickman JM. Gene expression heterogeneities in embryonic stem cell populations: origin and function. Curr Opin Cell Biol. 2011 Dec;23(6):650-6. doi: 10.1016/j.ceb.2011.09.007. Epub 2011 Oct 5.

23: Kunath T, Saba-El-Leil MK, Almousailleakh M, Wray J, Meloche S, Smith A. FGF stimulation of the Erk1/2 signalling cascade triggers transition of pluripotent embryonic stem cells from self-renewal to lineage commitment. Development. 2007 Aug;134(16):2895-902. doi: 10.1242/dev.02880.

24: Schröter C, Rué P, Mackenzie JP, Martinez Arias A. FGF/MAPK signaling sets the switching threshold of a bistable circuit controlling cell fate decisions in embryonic stem cells. Development. 2015 Dec 15;142(24):4205-16. doi: 10.1242/dev.127530. Epub 2015 Oct 28.

25: Jenuwein T, Allis CD. Translating the histone code. Science. 2001 Aug 10;293(5532):1074-80. doi: 10.1126/science. 1063127.

26: Hastreiter S, Skylaki S, Loeffler D, Reimann A, Hilsenbeck O, Hoppe PS, Coutu DL, Kokkaliaris KD, Schwarzfischer M, Anastassiadis K, Theis FJ, Schroeder T. Inductive and Selective Effects of GSK3 and MEK Inhibition on Nanog Heterogeneity in Embryonic Stem Cells. Stem Cell Reports. 2018 Jul 10;11(1):58-69. doi: 10.1016/j.stemcr.2018.04.019. Epub 2018 May 17.

27: Huang S. Non-genetic heterogeneity of cells in development: more than just noise. Development. 2009 Dec;136(23):3853-62. doi: 10.1242/dev.035139.

28: Balázsi G, van Oudenaarden A, Collins JJ. Cellular decision making and biological noise: from microbes to mammals. Cell. 2011 Mar 18;144(6):910-25. doi: 10.1016/j.cell.2011.01.030.

29: Gonzalez I, Molliex A, Navarro P. Mitotic memories of gene activity. Curr Opin Cell Biol. 2021 Apr;69:41-47. doi: 10.1016/j.ceb.2020.12.009. Epub 2021 Jan 14.

30: Jambhekar A, Dhall A, Shi Y. Roles and regulation of histone methylation in animal development. Nat Rev Mol Cell Biol. 2019 Oct;20(10):625-641. doi: 10.1038/s41580019-0151-1. Epub 2019 Jul 2.

31: Loh YH, Wu Q, Chew JL, Vega VB, Zhang W, Chen X, Bourque G, George J, Leong B, Liu J, Wong KY, Sung KW, Lee CW, Zhao XD, Chiu KP, Lipovich L, Kuznetsov VA, Robson P, Stanton LW, Wei CL, Ruan Y, Lim B, Ng HH. The Oct4 and Nanog transcription network regulates pluripotency in mouse embryonic stem cells. Nat Genet. 2006 Apr;38(4):431-40. doi: 10.1038/ng1760.

32: Levasseur DN, Wang J, Dorschner MO, Stamatoyannopoulos JA, Orkin SH. Oct4 dependence of chromatin structure within the extended Nanog locus in ES cells. Genes Dev. 2008 Mar 1;22(5):575-80. doi: 10.1101/gad.1606308. Epub 2008 Feb 18.

33: Festuccia N, Owens N, Papadopoulou T, Gonzalez I,
Tachtsidi A, Vandoermel-Pournin S, Gallego E, Gutierrez N, Dubois A, Cohen-Tannoudji M, Navarro P. Transcription factor activity and nucleosome organization in mitosis. Genome Res. 2019 Feb;29(2):250-260. doi: 10.1101/gr.243048.118. Epub 2019 Jan 17.

34: Heurtier V, Owens N, Gonzalez I, Mueller F, Proux C, Mornico D, Clerc P, Dubois A, Navarro P. The molecular logic of Nanog-induced self-renewal in mouse embryonic stem cells. Nat Commun. 2019 Mar 7;10(1):1109. doi: 10.1038/s41467-019-09041-z.

35: Kalkan T, Olova N, Roode M, Mulas C, Lee HJ, Nett I, Marks H, Walker R, Stunnenberg HG, Lilley KS, Nichols J, Reik W, Bertone P, Smith A. Tracking the embryonic stem cell transition from ground state pluripotency. Development. 2017 Apr 1;144(7):1221-1234. doi: 10.1242/dev.142711. Epub 2017 Feb 7.

36: Argelaguet R, Clark SJ, Mohammed H, Stapel LC, Krueger C, Kapourani CA, Imaz-Rosshandler I, Lohoff T, Xiang Y, Hanna CW, Smallwood S, Ibarra-Soria X, Buettner F, Sanguinetti G, Xie W, Krueger F, Göttgens B, RuggGunn PJ, Kelsey G, Dean W, Nichols J, Stegle O, Marioni JC, Reik W. Multi-omics profiling of mouse gastrulation at single-cell resolution. Nature. 2019 Dec;576(7787):487-491. doi: 10.1038/s41586-019-1825-8. Epub 2019 Dec 11.

37: Anderson KGV, Hamilton WB, Roske FV, Azad A, Knudsen TE, Canham MA, Forrester LM, Brickman JM. Insulin fine-tunes self-renewal pathways governing naive pluripotency and extra-embryonic endoderm. Nat Cell Biol. 2017 Oct;19(10):1164-1177. doi: 10.1038/ncb3617.

38: Berger SL, Kouzarides T, Shiekhattar R, Shilatifard A. An operational definition of epigenetics. Genes Dev. 2009 Apr 1;23(7):781-3. doi: 10.1101/gad.1787609.

39: Nicetto D, Zaret KS. Role of H3K9me3 heterochromatin in cell identity establishment and maintenance. Curr Opin Genet Dev. 2019 Apr;55:1-10. doi: 10.1016/j.gde.2019.04.013. Epub 2019 May 16.

40: Yadav T, Quivy JP, Almouzni G. Chromatin plasticity: A versatile landscape that underlies cell fate and identity. Science. 2018 Sep 28;361(6409):1332-1336. doi: 10.1126/science.aat 8950 .

41: Feldman N, Gerson A, Fang J, Li E, Zhang Y, Shinkai Y, Cedar H, Bergman Y. G9a-mediated irreversible epigenetic inactivation of Oct-3/4 during early embryogenesis. Nat Cell Biol. 2006 Feb;8(2):188-94. doi: 10.1038/ncb1353. Epub 2006 Jan 15.

42: Festuccia N, Gonzalez I, Navarro P. The Epigenetic Paradox of Pluripotent ES Cells. J Mol Biol. 2017 May 19;429(10):1476-1503. doi: 10.1016/j.jmb.2016.12.009. Epub 2016 Dec 15.

43: Carlini V, Policarpi C, Hackett JA. Epigenetic Inheritance is Gated by Naïve Pluripotency and Dppa2. bioRxiv 2021.05.11.443595; doi: https://doi.org/10.1101/2021.05.11.443595

44: Illingworth RS, Hölzenspies JJ, Roske FV, Bickmore WA, Brickman JM. Polycomb enables primitive endoderm lineage priming in embryonic stem cells. Elife. 2016 Oct 10;5:e14926. doi: 10.7554/eLife.14926. 
bioRxiv preprint doi: https://doi.org/10.1101/2021.06.22.449256; this version posted June 22, 2021. The copyright holder for this preprint (which was not certified by peer review) is the author/funder, who has granted bioRxiv a license to display the preprint in perpetuity. It is made available under aCC-BY-NC-ND 4.0 International license.
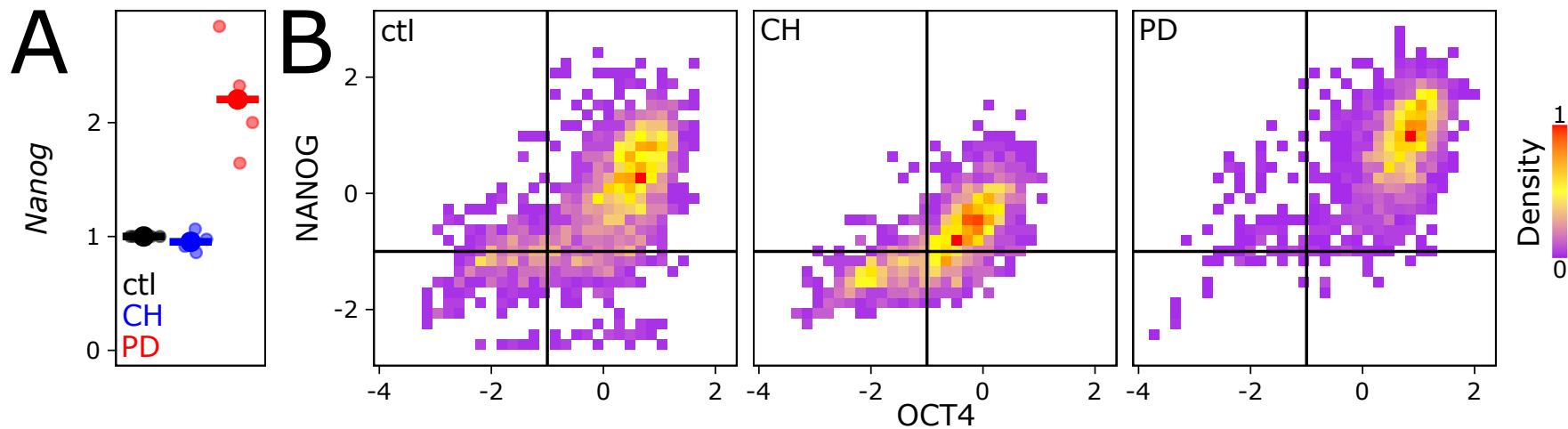

Supplementary Information, Fig. S 1. Effects of PD and CH treatment in ES cells. (A) Relative mRNA levels (ctl set to 1) of Nanog, measured by RT-qPCR and normalised to Tbp, upon 3d of PD or CH treatment of FCS+LIF cultured cells. (B) Quantification (z score) of NANOG and OCT4 immuno-staining in untreated E14Tg2a cells (ctl; $n=2053)$ and after $3 d$ of $\mathrm{CH}(\mathrm{n}=1554)$ or PD ( $\mathrm{n}=1857)$ treatment, as indicated.
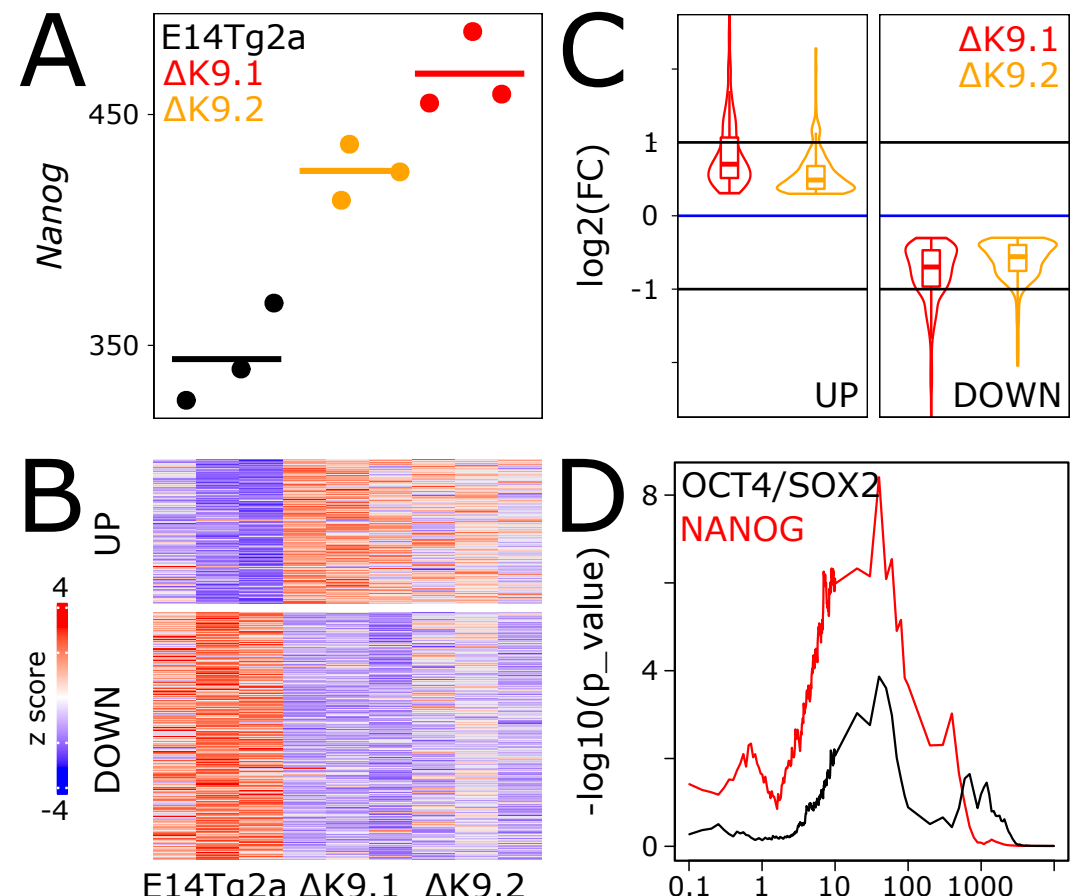

E14Tg2a $\Delta \mathrm{K} 9.1 \quad \Delta \mathrm{K} 9.2$

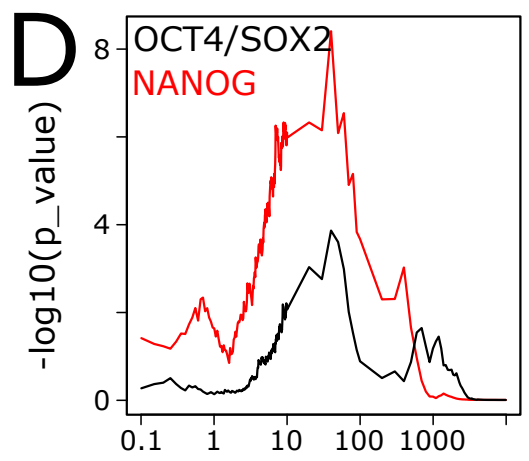

Supplementary Information, Fig. S 2. Gene expression consequences in $\Delta$ K9 cells. (A) Confirmation of Nanog upregulation in $\Delta K 9$ cells by RNA-seq (Transcripts Per Million, TPM). (B) Z scored heatmap of genes identified as differentially expressed in $\Delta \mathrm{K} 9$ cells. (C) Violin-Boxplot of gene expression fold-changes measured in $\Delta K 9.1$ and $\Delta$ K9.2 clones compared to wild-type E14Tg2a cells. (D) Statistical association (Y-axis, -log10(Fisher exact test $\mathrm{p}$-value)) between the differentially expressed genes shown in (B) with the presence of NANOG (red) or OCT4/SOX2 (black) binding sites as identified by ChIP-seq in a previous study33, as a function of the distance (X-axis, kb). 
bioRxiv preprint doi: https://doi.org/10.1101/2021.06.22.449256; this version posted June 22, 2021. The copyright holder for this preprint (which was not certified by peer review) is the author/funder, who has granted bioRxiv a license to display the preprint in perpetuity. It is made available under aCC-BY-NC-ND 4.0 International license.

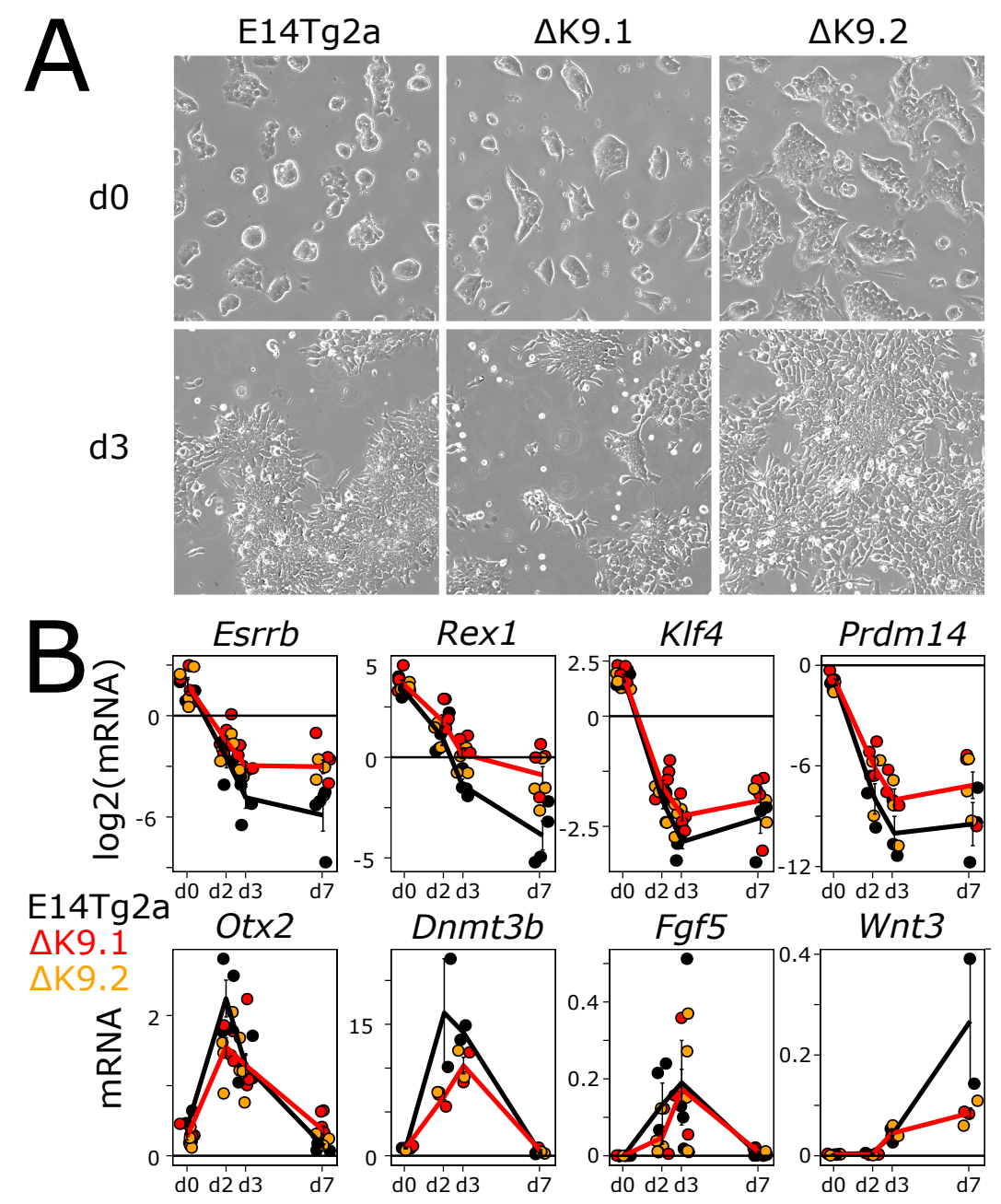

Supplementary Information, Fig. S 3. Differentiation of wild-type and $\Delta \mathbf{K} 9$ cells upon $2 \mathrm{i}+$ LIF withdrawal. (A) Representative bright-field photomicrographs of wild-type (E14Tg2a) and $\triangle K$ 9 cells cultured in 2i+LIF (top) and after 3 days of withdrawal (bottom). (B) RT-qPCR analysis of markers of naïve pluripotency (top) and differentiation (bottom) after 0, 2, 3 and 7 days of 2i+LIF withdrawal. Tbp was used for normalisation. 
bioRxiv preprint doi: https://doi.org/10.1101/2021.06.22.449256; this version posted June 22, 2021. The copyright holder for this preprint (which was not certified by peer review) is the author/funder, who has granted bioRxiv a license to display the preprint in perpetuity. It is made available under aCC-BY-NC-ND 4.0 International license.

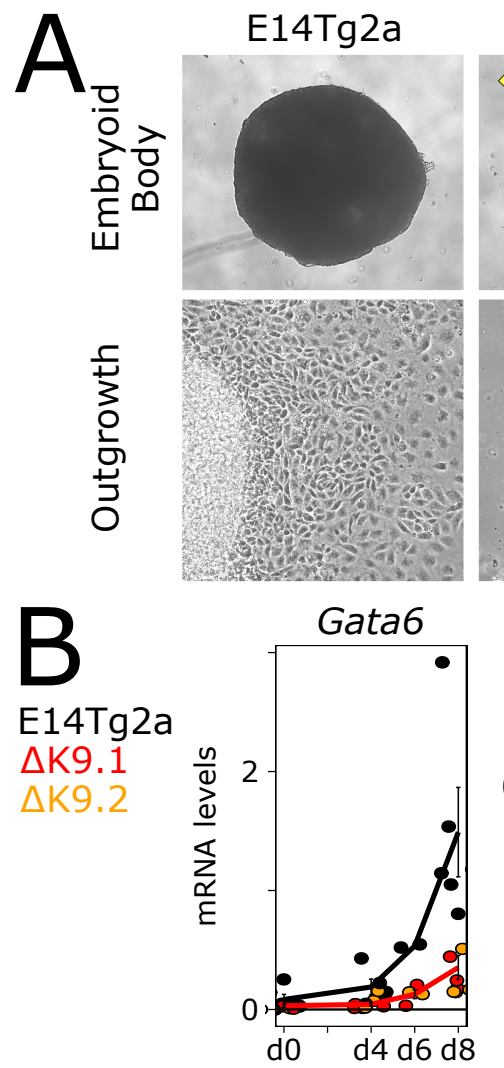

$\Delta K 9.1$
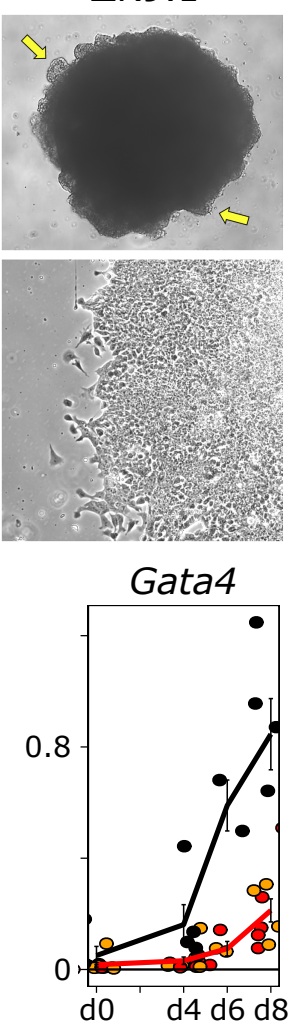

$\Delta \mathrm{K} 9.2$
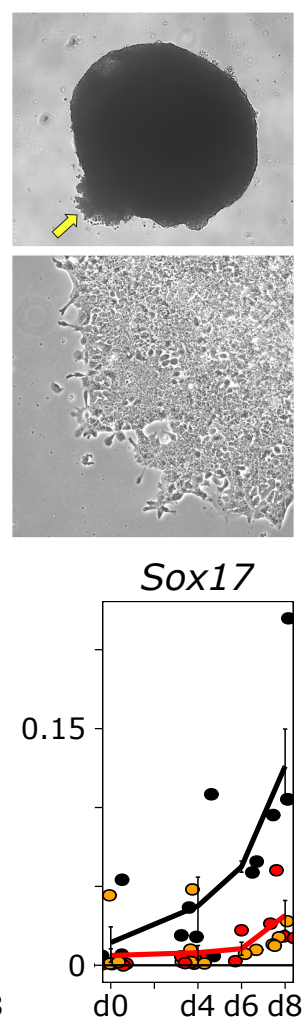

Supplementary Information, Fig. S 4. Differentiation of wild-type and $\Delta \mathrm{K} 9$ cells into embryoid bodies. (A) Representative bright-field photomicrographs of wild-type (E14Tg2a) and $\triangle \mathrm{K} 9$ embryoid bodies (top) and their derived cellular outgrowths (bottom). The arrows point to defective sealing of EBs periphery. (B) RT-qPCR analysis of endoderm markers after $0,4,6,8$ days of embryoid body differentiation. Tbp was used for normalisation. 
bioRxiv preprint doi: https://doi.org/10.1101/2021.06.22.449256; this version posted June 22, 2021. The copyright holder for this preprint (which was not certified by peer review) is the author/funder, who has granted bioRxiv a license to display the preprint in perpetuity. It is made available under aCC-BY-NC-ND 4.0 International license.
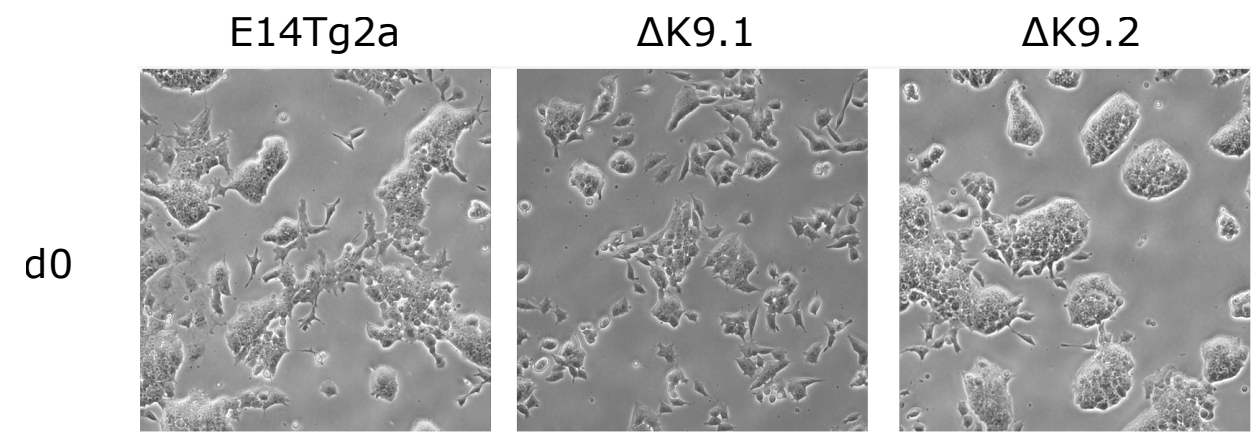

d1
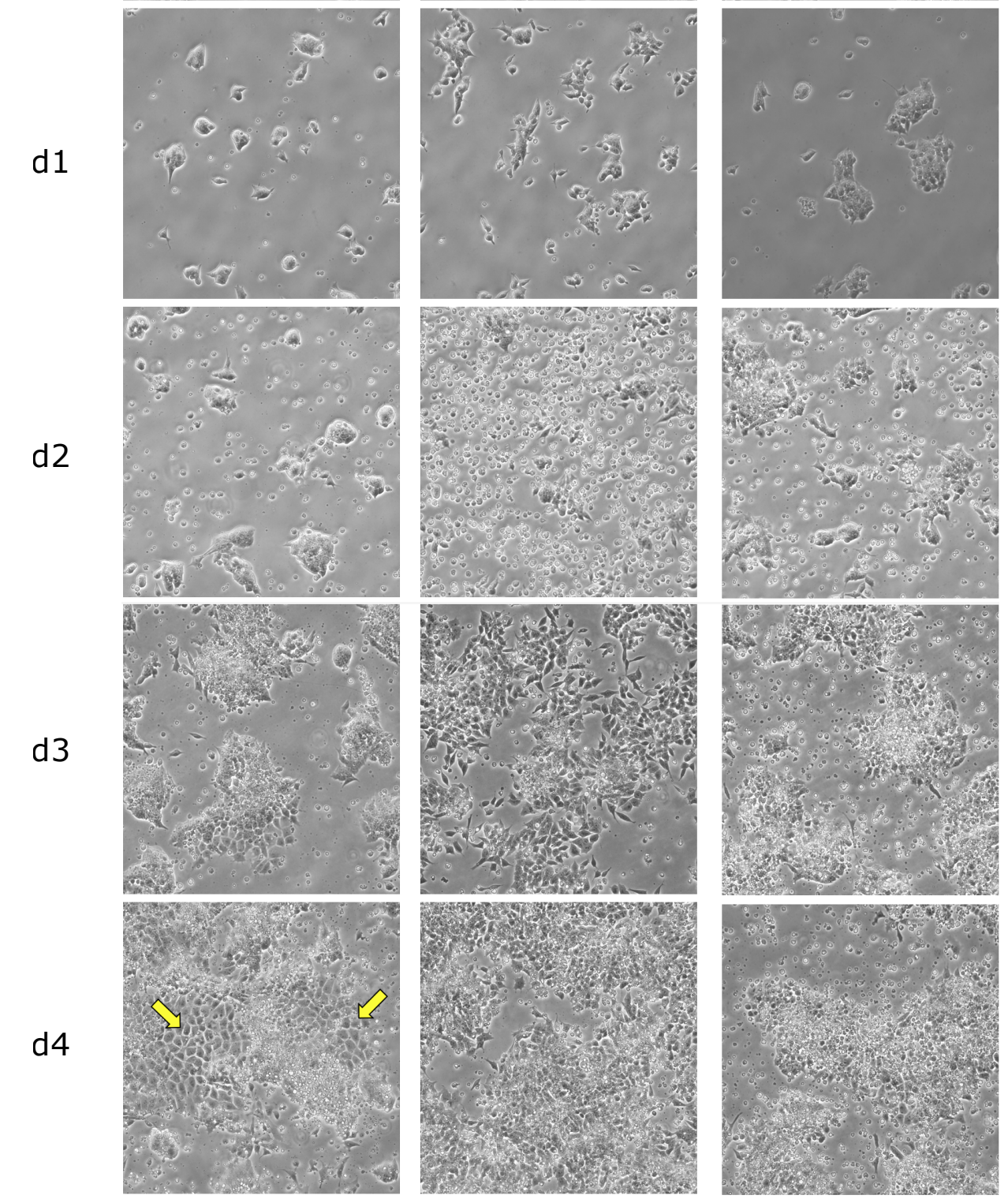

$\mathrm{d} 4$
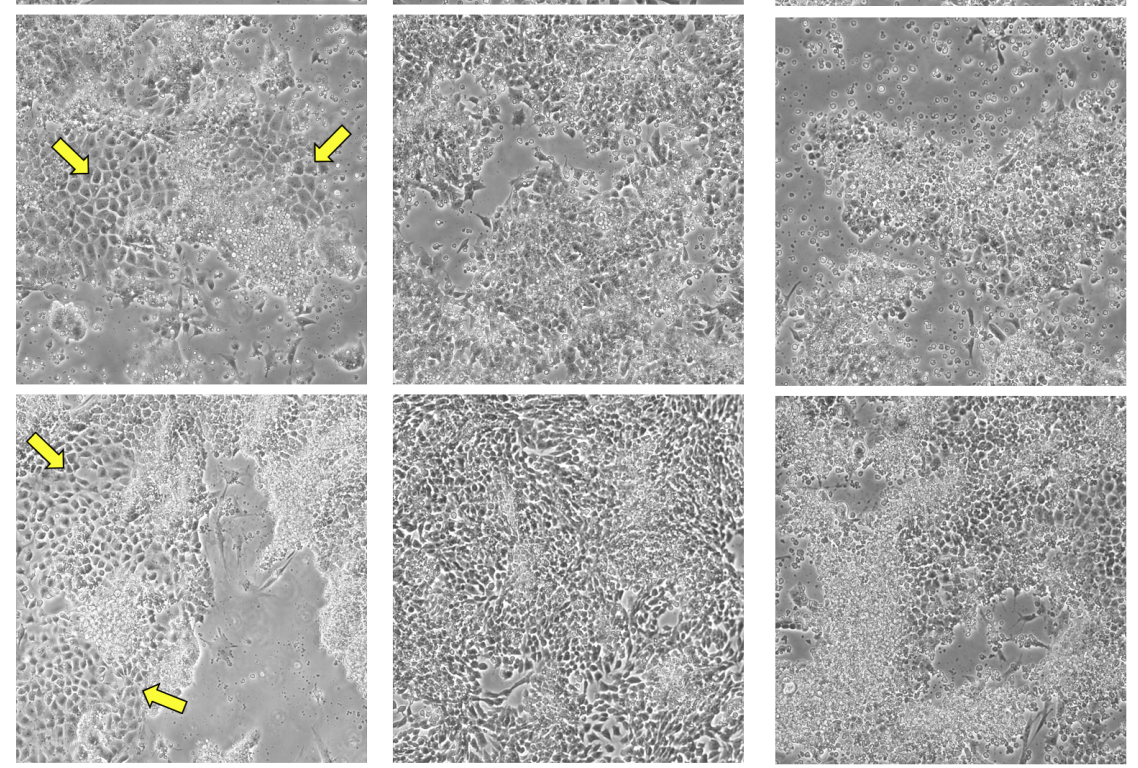

Supplementary Information, Fig. S 5. Directed differentiation of wild-type and $\Delta \mathrm{K} 9$ cells into primitive endoderm. Representative bright-field photomicrographs of wild-type (E14Tg2a) and $\Delta \mathrm{K} 9$ cells during their treatment with a primitive endoderm differentiation protocol. The arrows point to clusters of primitive endoderm cells. 